\title{
Laparoscopic Radical Prostatectomy: A Review
}

\author{
Pierluigi Bove, Anastasios D. Asimakopoulos, Fernando J. Kim, Giuseppe Vespasiani
}

Division of Urology, University of Tor Vergata (PB, ADA, GV), Rome, Italy and Denver Health Institute, University of Colorado (FJK), Denver, Colorado, USA

\begin{abstract}
Introduction: We offer an overview of the intra-, peri- and postoperative outcomes of laparoscopic radical prostatectomy (LRP) with the endpoint to evaluate potential advantages of this approach.

Materials and Methods: We conducted an extensive Medline literature search (search terms "laparoscopic radical prostatectomy" and "radical prostatectomy") from 1990 until 2007. Only full-length English language articles identified during this search were considered for this analysis. A preference was given to the articles with large series with more than 100 patients. All pertinent articles concerning localized prostate cancer were reviewed.

Conclusion: Pure LRP has shown to be feasible and reproducible but it is difficult to learn. Potential advantages over open surgery have to be confirmed by longer-term follow-up and adequately designed clinical studies.
\end{abstract}

Key words: prostate neoplasms; prostatectomy; laparoscopy; urinary incontinence; erectile dysfunction; training Int Braz J Urol. 2009; 35: 125-39

\section{INTRODUCTION}

Open radical retropubic prostatectomy $(\mathrm{RRP})$ is widely considered the treatment of choice for localized prostate cancer (1). After the first feasibility report by Schuessler (2) in 1997 and the standardization of the laparoscopic radical prostatectomy (LRP) technique by Guillonneau et al. (3) in 1999, a progressively growing interest has risen in the urologic community for LRP. Since then, the advantages and pitfalls of this minimally invasive approach have been increasingly reported in the literature by different authors (4). The lower blood loss and transfusion rate associated with the laparoscopic approach together with shorter hospital stay, reduced catheterization time, better pain control and the faster return to everyday activities seem the most encouraging improvements obtained (5). However, the interpretation of the data presented in the literature continues to be debated and has yet to be clarified.

This review reports intra-, peri- and post-operative outcomes of LRP with the endpoint to evaluate potential advantages of this approach.

\section{Historical Aspects}

In 1992 Schuessler, a non-academic, attempted the first LRP assisted by two endourologists with laparoscopic experience in renal surgery (6). These pioneers were able to successfully perform 9 LRP procedures, but found no benefit over open prostatectomy (2).

In 1997 Gaston, who had an extensive experience in laparoscopic pelvic floor reconstruction, started LRP (7) but only one year later Guillonneau et al. detailed their stepwise approach to transperitoneal LRP (3). These experiences were followed shortly 
by several European centers (8-11). In USA, even experienced laparoscopists remained very skeptical about LRP. Gill and Zippe, who at that time focused on renal laparoscopic surgery, were one of the few who established a program of laparoscopic pelvic surgery (12).

LRP has slowly risen in popularity. In 2002, a survey of laparoscopic activities in Germany and Switzerland revealed that $15 \%$ of the departments performed LRP, but only 5\% did more than 15 cases (13). In 2004, 19.2\% of German departments already offered LRP, whereas $26.9 \%$ preferred perineal, and $60.6 \%$ retropubic radical prostatectomy (14). In 2006, a multi-center study of more than 5800 patients was published treated with LRP by 50 surgeons in Germany (15).

\section{MATERIALS AND METHODS}

We conducted an extensive Medline literature search (search terms "laparoscopic radical prostatectomy" and "radical prostatectomy") from 1990 until 2007; only full-length English language articles identified during this search were considered for this analysis. A preference was given to the articles with larger series of more than 100 patients. The laparoscopic results were interpreted as whole regardless of the technical differences (transperitoneal versus extraperitoneal, antegrade versus retrograde dissection, number, disposition of the surgical ports, etc).

We have to underline that since 1997 the number of publications regarding the laparoscopic radical prostatectomy has greatly increased. A research in the Pubmed literature from 1990 until 1997, with the terms "laparoscopic radical prostatectomy" and "laparoscopic prostatectomy", produced less than 10 results; the majority of the articles publicized during this period concerned the laparoscopic pelvic lymphadenectomy in conjunction with radical perineal or retropubic prostatectomy in patients with prostate cancer. In the middle of the 90s the interest regarding laparoscopic pelvic lymphadenectomy (including urologic laparoscopy in general) diminished; the new methods for staging prostatic cancer that progressively appeared (based on the combination of Gleason score with PSA value) eliminated the indication of pelvic lymphadenectomy in more than $95 \%$ of the cases of prostate cancer potentially treated by surgical intervention.

After 1997 LRP became, in some centers, the surgical approach of choice for the treatment of the localized prostate cancer.

\section{INTRA- AND PERIOPERATIVE COMPLICATIONS}

The low conversion rates in all major series are a testimony to the careful introduction of LRP (16).With increasing experience, even challenging situations, such as cases following previous laparoscopic hernioplasty can be managed (17). In a recent multicenter study, technical reasons (i.e. adhesions, difficulties with the urethro-vesical anastomosis, malfunctioning of instruments) or uncertain tumor anatomy (i.e. risk of positive margins) caused the conversion to open surgery rather than intraoperative complications, such as bleeding or visceral injury (15). Bhayani et al. observed only $1.9 \%$ incidence of open conversions in a multi-institutional series citing prior pelvic surgery and morbid obesity as contributing factors (18). All of the comparative studies between LRP and RRP demonstrated a lower blood loss (LRP: $189-1100 \mathrm{~mL}$ vs. RRP: $550-1550 \mathrm{~mL}$ ) and transfusion rate with laparoscopy except one (19), where the higher transfusion rate observed in the LRP series is probably correlated to the different level of surgeon expertise (RRP $>800$, LRP $>60$ cases). The same applies to complication and reoperation rates (7,19-26).

A comparison of the identical number of patients $(n=1243)$ treated at two centers in Germany demonstrates similar patterns. A comprehensive description of incidence and types of complications following 567 consecutive LRPs over a 3-year period revealed a total, major, and minor complication rate of $17 \%, 4 \%$, and $14.6 \%$ respectively (27). Gonzalgo et al. applied a grading scheme designed to detail the frequency and severity of complications following LRP. A total of $34(13.8 \%)$ morbidities were encountered during 246 LRP cases, the majority (94.1\%) of which was self-limited (i.e. grade II-III). There were only $2(5.9 \%)$ grade IV complications (i.e. potentially life 
Table 1 - Update classification of surgical complications.

\begin{tabular}{|c|c|}
\hline Grade & Definition \\
\hline Grade I & $\begin{array}{l}\text { Any deviation from the normal postoperative course without the need for pharmacological treat- } \\
\text { ment or surgical, endoscopic, and radiological interventions. } \\
\text { Allowed therapeutic regimens are: drugs as antiemetics, antipyretics, analgesics, diuretics, electro- } \\
\text { lytes, and physiotherapy. This grade also includes wound infections opened at the bedside. }\end{array}$ \\
\hline Grade II & $\begin{array}{l}\text { Requiring pharmacological treatment with drugs other than such allowed for grade I complica- } \\
\text { tions. } \\
\text { Blood transfusions and total parenteral nutrition are also included. }\end{array}$ \\
\hline Grade III & Requiring surgical, endoscopic or radiological intervention. \\
\hline Grade IIIa & Intervention not under general anesthesia. \\
\hline Grade IIIb & Intervention under general anesthesia. \\
\hline Grade IV & Life-threatening complication (Including CNS complications)* requiring IC/ICU management. \\
\hline Grade IVa & Single organ dysfunction (Including dialysis). \\
\hline Grade IVb & Multiorgan dysfunction. \\
\hline Grade V & Death of a patient. \\
\hline Suffix “d” & $\begin{array}{l}\text { If the patient suffers from a complication at the time of discharge (see examples in Table-2), the } \\
\text { suffix "d" (for "disability") is added to the respective grade of complication. This label indicates } \\
\text { the need for a follow-up to fully evaluate the complication. }\end{array}$ \\
\hline
\end{tabular}

*Brain hemorrhage, ischemic stroke, subarrachnoidal bleeding, but excluding transient ischemic attacks. CNS = central nervous system; $I C=$ intermediate care; $I C U=$ intensive care unit. Source = Dindo D, Demartines $N$, Clavien PA = Classification of surgical complications $=$ a new proposal with evaluation in a cohort of 6336 patients and results of a survey. Ann Surg. 2004; 240: 205-13.

threatening requiring intensive care unit management) and no grade $\mathrm{V}$-complication (i.e. death) (28). The classification of the complication degrees mentioned above was based on the updated Clavien system that is reported in Table-1. Application of the updated Clavien grading scheme (Table-1) in the report of Guilloneau et al. (27) also resulted in approximately $90 \%$ of LRP complications classified as grade II or III. The remaining $10 \%$ of complications could be classified as grade 1 and there were no grade IV or $\mathrm{V}$ complications (Table-2). At centers of expertise, conversion and reintervention have become a rare event (less than $1 \%$ ).

From a large number of other studies $(10,27,29-31)$ we could deduce that there is a $4 \%$ (1-6.1\%) of intraoperative complications (rectal injury $1.5 \%(1-2.4 \%)$, ileal or sigmoid injury $1 \%$ $(0.8-1.9 \%)$, epigastric vessels injury $0.27 \%(0-0.5 \%)$, bladder injury $0.81 \%(0-1.6 \%)$, ureteral injury $0.36 \%$ (0-0.7\%), external iliac vein injury $0.09 \%(0-0.8 \%)$. The early postoperative complications amounted to $20.7 \%$ of cases and they mainly included anastomotic

Table 2 - Examples of the application of the update classification with regard to the complications of 2 laparoscopic radical prostatectomy series.

\begin{tabular}{lcccc}
\hline & Grade I & Grade II-III & Grade IV & Grade V \\
\hline Gonzalgo et al. (28) & $0 \%$ & $94.1 \%$ & $5.9 \%$ & $0 \%$ \\
Guillonneau et al. (27) & $10 \%$ & $90 \%$ & $0 \%$ & $0 \%$ \\
\hline
\end{tabular}


leakage (10.3\%), hemorrhagic complications $(2.8 \%)$, urinary retentions $(2.35 \%)$ and ileus $(1.4 \%)$. However, anastomotic stricture, phlebitis/embolism/thrombosis, urinary tract infections, neurological complications, fistulas, lymphorrea, trocar hernia accounted for percentages below $1 \%$. Two more recent series confirm these data $(15,32)$ (Tables-3 to 6).

The necessity of transfusion varied from $1.6 \%$ to $31 \%$ among the analyzed series $(15,29-32)$, Table-7.
A particular area of concern is pulmonary embolism (PE) that is the main cause of death in the $0.5 \%$ patients who die perioperatively after cancer surgery (33). The true incidence of symptomatic venous thromboembolism (VTE) in patients undergoing LRP is still unclear. Recently, Secin et al. published a multi-institutional study of VTE and PE in prostate cancer patients undergoing LRP (with or without robotic assistance). Of 5951 patients retrospectively evaluated, 31 developed symptomatic VTE $(0.5 \%$;

Table 3 - Intraoperative morbidity of laparoscopic radical prostatectomy in early series with more than 100 patients.

\begin{tabular}{lcccccc}
\hline & $\begin{array}{c}\text { Hoznek } \\
\text { et al. (29) }\end{array}$ & $\begin{array}{c}\text { Turk } \\
\text { et al. (10) }\end{array}$ & $\begin{array}{c}\text { Rassweiler } \\
\text { et al. (30) }\end{array}$ & $\begin{array}{c}\text { Guillonneau } \\
\text { et al. (27) }\end{array}$ & $\begin{array}{c}\text { Eden } \\
\text { et al. (31) }\end{array}$ & $\begin{array}{c}\text { Total } \\
(\%)\end{array}$ \\
\hline Number of patients & 134 & 125 & 180 & 567 & 100 & \\
Rectal injury & $1.4 \%$ & $2.4 \%$ & $1.6 \%$ & $1.4 \%$ & $1 \%$ & 1.5 \\
Ileal or sigmoid injury & - & $0.8 \%$ & - & $1.9 \%$ & - & 1 \\
Epigastric vessels injury & - & - & - & $0.5 \%$ & - & 0.27 \\
Bladder injury & - & - & - & $1.6 \%$ & - & 0.81 \\
Ureteral injury & - & - & - & $0.7 \%$ & - & 0.36 \\
External iliac vein injury & - & $0.8 \%$ & - & - & - & 0.09 \\
Total & $1.4 \%$ & $4 \%$ & $1.6 \%$ & $6.1 \%$ & $1 \%$ & 4.03 \\
\hline
\end{tabular}

Table 4 -Early postoperative complications in early series with more than 100 patients.

\begin{tabular}{lcccccc}
\hline & $\begin{array}{c}\text { Hoznek } \\
\text { et al. (29) }\end{array}$ & $\begin{array}{c}\text { Turk } \\
\text { et al. (10) }\end{array}$ & $\begin{array}{c}\text { Rassweiler } \\
\text { et al. (30) }\end{array}$ & $\begin{array}{c}\text { Guillonneau } \\
\text { et al. (27) }\end{array}$ & $\begin{array}{c}\text { Eden } \\
\text { et al. (31) }\end{array}$ & $\begin{array}{c}\text { Total } \\
(\%)\end{array}$ \\
\hline Anastomotic leakage & 134 & 125 & 180 & 567 & 100 & \\
Hemorrhagic complications & $2.9 \%$ & $13.6 \%$ & $19.4 \%$ & $10 \%$ & $1 \%$ & 10.3 \\
Urinary retention & - & $1.6 \%$ & $10 \%$ & $1.7 \%$ & $1 \%$ & 2.8 \\
Ileus & - & - & - & $4.5 \%$ & - & 2.35 \\
Anastomotic stricture & - & $3.2 \%$ & $2.7 \%$ & $1 \%$ & $1 \%$ & 1.4 \\
Phlebitis/thrombosis/embolism & - & $1.6 \%$ & $3.3 \%$ & - & - & 0.7 \\
Neurological complications & $0.7 \%$ & $2.4 \%$ & - & $0.3 \%$ & - & 0.6 \\
Urinary tract infections & $0.7 \%$ & - & - & $0.5 \%$ & $1 \%$ & 0.45 \\
Fistulas & - & - & - & - & - & 0 \\
Lymphorrea & $0.7 \%$ & $0.8 \%$ & $1.1 \%$ & - & - & 0.36 \\
Trocar hernia & $2.9 \%$ & - & - & $0.1 \%$ & - & 0.45 \\
Other & - & - & $0.5 \%$ & - & $1 \%$ & 0.18 \\
Total & $2.2 \%$ & $0.8 \%$ & $0.5 \%$ & $1.4 \%$ & - & 1.17 \\
\hline
\end{tabular}


Table 5 - Main intra and postoperative complications of laparoscopic radical prostatectomy in late series (Lein et al., ref. 32).

\begin{tabular}{lc}
\hline Intra and Postoperative Complications & $\mathbf{\%}$ \\
\hline Rectal injury & 3.3 \\
Ileus/sub-ileus & 2.5 \\
Blood transfusion & 2.2 \\
Neurologic lesion & 1.8 \\
Bowel injury & 0.9 \\
Thrombosis/embolism & 0.8 \\
Bladder injury & 0.4 \\
Renal failure & 0.3 \\
Ureteral injury & 0.1 \\
Other & 0.6 \\
Total complication rate & 12.9 \\
\hline
\end{tabular}

Table 6-Laparoscopic radical prostatectomy in late series (German Laparoscopic Working Group, ref. 15).

\begin{tabular}{lc}
\hline Complications & $\mathbf{\%}$ \\
\hline Bleeding & 2.2 \\
Rectal lesion & 1.7 \\
Extravasation & 2.4 \\
Thromboembolism & 0.6 \\
Total complication rate & 8.9 \\
\hline
\end{tabular}

95\% confidence interval $[\mathrm{CI}], 0.4 \%, 0.7 \%)$. Among patients with an event, 22 (71\%) had deep venous thrombosis (DVT) alone, 4 had PE without identified DVT, and 5 had both. Two patients died of PE. Prior DVT (odds ratio $[\mathrm{OR}]=13.5 ; 95 \% \mathrm{CI}, 1.4,61.3$ ), current tobacco smoking $(\mathrm{OR}=2.8 ; 95 \% \mathrm{CI}, 1.0,7.3)$, larger prostate volume $(\mathrm{OR}=1.18 ; 95 \% \mathrm{CI}, 1.09$, $1.28)$, patient re-exploration $(\mathrm{OR}=20.6 ; 95 \% \mathrm{CI}$, $6.6,54.0)$, longer operative time $(\mathrm{OR}=1.05 ; 95 \% \mathrm{CI}$, $1.02,1.09)$, and longer hospital stay $(\mathrm{OR}=1.05 ; 95 \%$ CI, 1.01, 1.09) were associated with VTE in univariate analysis. Neoadjuvant therapy, body mass index, surgical experience, surgical approach, pathologic stage, perioperative transfusion, and heparin administration were not significant predictors. The authors concluded that the incidence of symptomatic VTE after LRP is low and that these data do not support the administration of prophylactic heparin to all patients undergoing LRP, especially those without risk factors for VTE (34).

\section{SURGICAL MARGINS AND CANCER CONTROL}

In the most representative series of laparoscopic radical prostatectomy follow-up is not long enough to give a definitive oncologic evaluation of its surgical efficacy. Nevertheless, preliminary data reported in these papers suggest that this approach can guarantee the same results in terms of cancer control as those of open procedures (35-38).

No cases of trocar track metastasis or local relapse have so far been reported after LRP although these complications have been reported after extensive nephrectomy and nephroureterectomy (39). The extraperitoneal approach avoids this potential risk of intraperitoneal dissemination of tumor cells (38).

Depending on the surgical approach the location of surgical positive margins differs: the apex with the RRP, the bladder neck with the Perineal radical prostatectomy, the posterolateral regions of the prostate (that contain the neurovascular bundles and prostatic pedicles) in the LRP (probably because of the instrument axis and its smaller amplitude during dissection of the prostatic pedicles, which are closer to the trocar ports) (40-42).

As concerns oncologic results of RP, these are evaluated based on the rate of positive surgical margins (that reflect the quality of tumor excision) and survival with no biological progression.

Table 7 - Transfusion rate.

\begin{tabular}{lc}
\hline Series & Transfusion Rate \% \\
\hline Hoznek et al. (29) & 2.9 \\
Turk et al. (10) & 1.6 \\
Rassweiler et al. (30) & 3.1 \\
Guillonneau et al. (27) & 4 \\
Eden et al. (31) & 3 \\
Lein et al. (32) & 2.2 \\
Rassweiler et al. (15) & 4.1 \\
\hline
\end{tabular}


The positive surgical margins (defined as the presence of cancer at the inked margin of resection on the prostatectomy specimen, (40)) influence the prognosis, as they determine a higher risk of biochemical, local and systemic progression (43).

The results on the positive surgical margin rate are summarized in Table- 8 . We have to consider that major series reported in literature, include the first patients operated when the LRP was in early development and the surgeons were either developing the technique or learning its application. More recent data, suggest a significant decrease of positive surgical margins over time without any evidence of downward stage migration, in both organ-confined and non-organ-confined disease (37,44-46).

Given the fact that LRP has only been regularly performed since 1998, information about long term follow-up is unavailable. Although the data continue to mature for LRP series, the short-term biochemical-free recurrence results appear similar to those reported in open radical prostatectomy experi- ence with a biochemical recurrence-free probability between 83 and $94.5 \%$ at 3 years $(37,44-47)$ (Table9).

Long-term results on biochemical recurrencefree survival are eagerly awaited.

\section{CONTINENCE}

The wide range of incontinence rates reported in the literature indicates the difficulty to obtain an accurate assessment of urinary control after radical prostatectomy. Moreover, the lack of a uniform definition of post-operative continence is crucial to this problem. While some studies use a strict definition of continence as a "no pads" condition, others allow the use of 1 precautionary pad per day as determined by patient report.

LRP seems initially to offer an earlier continence recovery, but the number of continent patients at one year follow up is comparable to that after ORP. In

Table 8 - Cancer control: positive surgical margin rate.

\begin{tabular}{lrll}
\hline & pT2 & pT3 & Overall Positive Surgical Margin Rate \\
\hline Guillonneau et al. (1000 pts) (ref. 37) & $15.5 \%$ & $31 \%$ & $19.2 \%$ \\
Rassweiler et al. (500 pts) (ref. 44) & $7.4 \%$ & $31.8 \%$ & $19 \%$ \\
Stolzenburg et al. (700 pts) (ref. 45) & $10.8 \%$ & $31.2 \%$ & $19.8 \%$ \\
Touijer et al. (500 pts) (ref. 46) & $8.2 \%$ & $17.2 \%$ & $11 \%$ \\
\hline
\end{tabular}

Table 9 - Progression free.

\begin{tabular}{lccc}
\hline & $\begin{array}{c}\text { 3-year Biochemical } \\
\text { Recurrence-Free } \\
\text { Probability }\end{array}$ & $\begin{array}{c}\text { 5-year Biochemical } \\
\text { Recurrence-Free } \\
\text { Probability }\end{array}$ & Definition of Progression \\
\hline Montsouris (37) & $90.5 \%$ & PSA $>0.1 \mathrm{ng} / \mathrm{mL}$ confirmed by a \\
second increase & $2 \mathrm{PSA}$ values \\
Heilbronn (44) & $83 \%$ & $73.1 \%$ & $>0.2 \mathrm{ng} / \mathrm{mL}$ \\
Johns Hopkins (47) & & & $2 \mathrm{PSA}$ values \\
& $94.5 \%$ & & $>0.2 \mathrm{ng} / \mathrm{mL}$ \\
\hline
\end{tabular}


incontinent patients, even the severity of incontinence seems to be similar after the two procedures (48).

The Montsouris group reported on a series of 255 patients with 12-months follow-up after LRP that 209 patients $(82.3 \%)$ were pad free, 31 (12\%) needed one pad a day, and 15 patients $(5.9 \%)$ had urinary incontinence requiring more than two pads a day (49). Stolzenburg et al., using the same validated questionnaire, reported the results on 700 extraperitoneal LRPs. Among 500 patients who had 6 months follow-up, 419 patients $(83.8 \%)$ were pad free, $52(10.4 \%)$ needed one to two pads a day, and 29 patients $(5.8 \%)$ had urinary incontinence requiring more than two pads a day (45) (Table-10). Rassweiler et al. reported an experience of 450 LRPs; among the 300 men with 12-months follow-up, the continence rate was $91 \%$. However, the authors did not state the definition of continence or the methodology of measurement used in their analysis (50). Galli et al. reported that the incidence of long-term continence following laparoscopic prostatectomy is $91.7 \%$, which appears to be equal to that reported by major centers using either open or laparoscopic access (51).

Recently Rocco et al. demonstrated that a posterior reconstruction of the rhabdosphincter allowed a rapid recovery of the continence after transperitoneal videolaparoscopic radical prostatectomy.

They report that the musculo-fascial plate, comprised of the striated sphincter, Denonvilliers' fascia, and the dorsal aspect of the prostate, acts as a suspensory system for the prostato-membranous urethra and that its division during RP results in the loss of the posterior cranial insertion of the sphincter, the caudal displacement of the sphincteric complex, and a prolapse of the perineum. Therefore, they propose to reconstruct this musculo-fascial plate by joining the posterior median raphe with the connected dorsal wall of the RS to the residuum of the Denonvilliers fascia and to suspend it to the posterior wall of the bladder, 1-2 cm cranially and dorsally to the new bladder neck (52).

Therefore, a two-arm prospective comparative trial was carried out with 31 patients recruited for each arm. Group A underwent standard VLRP and group B underwent VLRP with RS reconstruction (VLRP-R). Continence was defined as no pads or one diaper/24 $\mathrm{h}$ and was assessed 3, 30, and $90 \mathrm{~d}$ after the procedure. At catheter removal, $74.2 \%$ versus $25 \%$ (p $=0.0004$ ) of patients were continent with the VLRP-R technique versus VLRP, respectively. A statistically significant difference was present at $30 \mathrm{~d}(83.8 \%$ vs. $32.3 \% ; \mathrm{p}=0.0001)$. At $90 \mathrm{~d}$ the difference, although still present, was not statistically significant $(92.3 \%$ vs. $76.9 \% ; p=0.25)(52)$.

Nguyen et al. confirmed the earlier recovery of continence after posterior musculo-fascial plate reconstruction during robotic and laparoscopic prostatectomy. The authors evaluated the mean length of the membranous urethra on transrectal ultrasound(TRUS) measured before and after RP and, also, before the musculo-fascial suture that resulted 15.6, 12 and 14 $\mathrm{mm}$, respectively. They concluded that reconstruction restored the length of the transected membranous urethra by a mean of $2 \mathrm{~mm}$ (53).

\section{POTENCY}

Comparison of data is not easy because most series of LRP include potency data only on a small subset of patients, some group report only the rate of spontaneous erection and, additionally, potency depends on preoperative sexual function, patient age, degree of neurovascular bundle preservation and fol-

Table 10 - Continence between 2 series using the same validated questionnaire.

\begin{tabular}{lccc}
\hline & Pad Free & 1-2 Pads/Day & $>$ 2 Pads/Day \\
\hline $\begin{array}{l}\text { Montsouris group } \\
\quad(12 \text { months follow-up) (ref. 49) }\end{array}$ & $82.3 \%$ & $12 \%$ & $5.9 \%$ \\
$\begin{array}{l}\text { Stolzenburg et al. } \\
\text { (6 months follow-up) (ref. 45) }\end{array}$ & $83.8 \%$ & $10.4 \%$ & $5.8 \%$ \\
\hline
\end{tabular}


low-up, since potency can return months or years after surgery (54).

Laparoscopic nerve sparing prostatectomy is performed by dissecting the pedicles in an antegrade fashion. This maneuver releases the neurovascular bundle laterally and allows the dissection of the prostate. The delicate neurovascular bundle (NVB) is intimately related to the postero-lateral surface of the prostate. As such, complete avoidance of any thermal or electrical energy during lateral pedicle transection and NVB release comprises a hallmark principle during open surgery. Recently, Ong et al. provided evidence in the survival canine model that the use of hemostatic energy sources (monopolar cautery, bipolar cautery, ultrasound scissors) during NVB release was associated with significantly decreased erectile response to cavernous nerve stimulation (55). However, the use of conventional dissection with hemostatic suture ligatures did not compromise the erectile response to nerve stimulation. Current laparoscopic and robotic techniques for lateral pedicle transection fall short in this important regard, typically using either monopolar or bipolar electrocautery, or ultrasound energy with the harmonic scalpel, with or without clips.

Once postoperative potency is established patients reported ability to achieve sexual intercourse with or without the use of PDE-inhibitors. Potency rates after bilateral nerve sparing LRP have been reported from $33 \%$ to $67 \%$ in various series worldwide. Most experts agree that at least 18 months of follow-up is necessary to assess potency outcomes adequately (54).

Of their initial 550 patients, Guillonneau et al. reported in a subset of 47 consecutive patients less than 70 years of age, preoperatively potent with bilateral nerve sparing, 31 patients $(66 \%)$ able to have intercourse with or without sildenafil (49). Rassweiller et al. reported that, in a subset of 41 patients preoperatively potent with bilateral nerve sparing (BNS), a $67 \%$ was able to have intercourse after the surgical procedure (50). Curto et al. referred that, in a subset of 137 patients that underwent BNS, 58.5\% could have intercourse with or without sildenafil post-operatively (54) (Table-11).

A recent review of Mulhall et al. (56) underlines on the role of the artery-sparing radical prostatectomy. In fact, not all patients in whom the neurovascular bundles are preserved recover erectile function after radical prostatectomy. A significant proportion of these men have vascular abnormalities that can impact erectile function recovery after radical prostatectomy. The authors describe the available evidence supporting the need to spare not only the nerves, but also the arteries to improve erectile function recovery after radical prostatectomy.

\section{LEARNING CURVE: THE IMPORTANCE OF THE MENTOR}

Laparoscopic radical prostatectomy has been evaluated at several centers in the United States as a treatment option for localized prostate cancer. It is a technically difficult operation to perform with a steep learning curve. Fifty procedures seem to be necessary to decrease complications and increase functional outcomes (57).

A learning curve includes the necessity for continuous self-evaluation in terms of cancer control,

Table 11 - Potency rates (with or without use of PDE5-I) after bilateral nerve sparing (BNS) procedure for patients preoperatively potent.

\begin{tabular}{lcc}
\hline Series & Number of BNS & $\begin{array}{c}\text { \% of Postoperative Potency with or } \\
\text { without PDE5-I }\end{array}$ \\
\hline Guillonneau et al. (ref. 49) & 47 & $66 \%$ \\
Rassweiler et al. (ref. 50) & 41 & $67 \%$ \\
Curto et al. (ref. 54) & 137 & $58.5 \%$ \\
\hline
\end{tabular}


continence and potency. Many different methods can be used to acquire the technique: dry lab, animal live lab, cadaveric laparoscopic dissection or mentoring with an expert. All of these steps may not be essential, as laparoscopic radical prostatectomy is not too dissimilar to open prostatectomy.

The transfer of technology and surgical experience/aptitude is problematic. It has been clearly shown that weekend training courses and weekend laboratory sessions do not translate into clinical ability to perform these procedures. Colegrove et al. observed that participants in these courses rarely perform these procedures in clinical practice (58).

The transfer of training from open surgical experience to newly introduced laparoscopic skills does not occur, emphasizing the need for intensive training.

These common difficulties clearly highlight the importance of mentoring programs. The mentor is an expert in laparoscopic technique able to direct trainee operative maneuvers increasing his efficiency. Lack of progression is often cited as the most common reason for open conversion during a laparoscopic procedure; in this case the mentor ensures forward progression. The most difficult aspects of this procedure, such as suturing the dorsal vein complex and urethrovesical anastomosis, bladder neck dissection and dissection off of the rectum cannot be effectively learned through laboratory simulation.

Fabrizio et al. were the first to describe a mentorship program designed to expedite performance of laparoscopic radical prostatectomy. They invited a surgeon (mentor) who had performed 200 cases to instruct a fellowship trained laparoscopist (trainee). From March 2001 through September 2001 they performed 30 laparoscopic radical prostatectomies. The mentor performed the first 12 procedures with the trainee acting as assistant (group 1). The subsequent 18 procedures were performed by the trainee with the mentor acting as assistant (group 2). A final set of 20 procedures was performed by the trainee alone using 1 of 3 urological residents as an assistant (group 3). The transperitoneal approach was used and all suturing was intracorporeal. There was not any statistical difference in terms of median operative time between the groups 1-2 and 2-3 but only between 1-3. Mean estimated blood loss was comparable in groups 1 to
3 and not statistically different. Hospital stay was 3 days in all groups. Catheter time decreased as confidence was gained with the procedure (range 6 to 33 days). Final pathological stage was compared among the 3 groups. There was an overall increase in positive margins in groups 1 to $3(16 \%, 22 \%$ and $30 \%$, respectively, p not significant). However, the positive margin rate for stage pT2 disease was similar at $15.5 \%$ for groups 1 and 2, and 14\% for group 3 (57).

Similar results were obtained in the mentorguided experience of Skrekas et al. (59).

The authors concluded that an intensive, mentor initiated approach can decrease the learning curve and maintain outcomes.

Recently, Stolzenburg et al. suggested a modular training program for residents with no prior experience with open pelvic surgery in endoscopic extraperitoneal radical prostatectomy (EERPE). They divided the technique into 12 segments with 5 levels of difficulty. Then they designed a training program, where the resident learned the procedure in a mentor-defined schedule. During each educational EERPE, the trainee only performed the operative steps corresponding to his acquired skill level. The mentor performed the remaining parts of the EERPE, with the trainee assisting. The first 50 and consequent 100 cases performed by the residents were compared to the first 50 and last 100 cases (cases 521-621) performed by the mentor. Two residents with no prior experience with open pelvic surgery participated in the study, and required 43 and 38 procedures respectively, until they were considered to be competent. The initial 50 procedures performed completely independently by the residents had mean operative times of 176 and 173 minutes. There were 2 intraoperative rectal injuries (one patient developed recto-urethral fistula), 1 hemorrhage, and 1 lymphocele, postoperatively. The positive margin rate for $\mathrm{pT} 2$ disease was 14.3 and $11.5 \%$, and for pT3 tumors 38.8 and $29.1 \%$, respectively. After an additional 100 procedures operated by the same residents, mean operative times were 142 and 146 minutes. There was one patient who needed a transfusion. Postoperative complications requiring re-intervention were 1 hemorrhage, 2 anastomotic leakages and 4 symptomatic lymphoceles. The positive margin rate for pT2 disease was $12.8 \%$ and $6.5 \%$, and for pT3 tumors $33.3 \%$ and $26.3 \%$ respectively. 
No statistical significant differences were observed when comparing with the mentors cases.

The authors concluded that residents with no prior experience in open surgery of the pelvis can adhere to the modular training scheme and successfully perform the EERPE procedure with similar risk of complications compared to the tutor (60).

\section{COST COMPARISON OF LRP VERSUS RRP}

Despite the advantages of LRP regarding its minimally invasive character, the operative times for this procedure have been consistently longer than those of RRP (19-21) and the cost of the disposable operating room equipment is greater, suggesting that LRP is more expensive than RRP. Given the large number of men diagnosed with prostate cancer and presumably seeking treatment, it is desirable that treatment options are not only efficacious but also cost effective.

Anderson et al. analyzed the cost data from a single institution comparing LRP and RRP. They concluded that the total cost of the procedure was significantly more for LRP than for RRP (US\$ 6760 vs. US\$ 5253, $\mathrm{p}<0.001)$. Most of this difference was due to surgical supply (US\$ 1202 vs. US\$ 145, p < 0.001 ) and operating room costs (US\$ 1601 LRP vs. US\$ 1141 RRP, $p<0.001)$. The room and board and pharmacy costs were significantly lower for LRP than for RRP because of the shorter mean length of stay. The laboratory/radiology and pathology costs were not significantly different (61) (Table-12).

\section{CONCLUSIONS}

After only a few years since its introduction, mid-term outcomes of LRP appear promising with regards to complications, oncologic and functional results, and have achieved equivalence to open surgery. Presently, a lower intraoperative blood loss and transfusion rates seem to be the most significant data in favor of LRP. The operating time is still somewhat longer, but many centers have already reported comparable operative times to open surgery. Further
Table 12 - Costs comparison of laparoscopic radical prostatectomy (LRP) vs. retropubic radical prostatectomy (RRP), ref. 61.

\begin{tabular}{lcc}
\hline & LRP (US\$) & RRP (US\$) \\
\hline Surgical supply & 1202 & 145 \\
Operating room costs & 1601 & 1141 \\
Room and board costs & 496 & 710 \\
Pharmacy costs & 243 & 267 \\
Laboratory/histology & 682 & 667 \\
Radiology & 28 & 34 \\
Transfusions & 0 & 80 \\
Surgeon & 1668 & 1594 \\
Total & 6760 & 5253 \\
\hline
\end{tabular}

potentials of LRP are related to video-endoscopy, providing optimal visualization of the operating field. This may lead to better preservation of the structures around the urinary sphincter, improve apical dissection and preservation of the neurovascular bundle. All these potential advantages must be confirmed by longer-term follow-up and adequately designed clinical studies.

At the moment, the LRP costs are significantly greater than the costs of RRP, and this is predominantly due to the higher surgical supply and operating room costs.

New disposable instruments and acquired experience in LRP may significantly decrease the cost of the procedure.

\section{CONFLICT OF INTEREST}

None declared.

\section{REFERENCES}

1. Walsh PC: Radical prostatectomy for localized prostate cancer provides durable cancer control with excellent quality of life: a structured debate. J Urol. 2000; 163: 1802-7.

2. Schuessler WW, Schulam PG, Clayman RV, Kavoussi LR: Laparoscopic radical prostatectomy: initial shortterm experience. Urology. 1997; 50: 854-7. 
3. Guillonneau B, Cathelineau X, Barret E, Rozet F, Vallancien G: Laparoscopic radical prostatectomy: technical and early oncological assessment of 40 operations. Eur Urol. 1999; 36: 14-20.

4. Omar AM, Townell N: Laparoscopic radical prostatectomy a review of the literature and comparison with open techniques. Prostate Cancer Prostatic Dis. 2004; 7: 295-301.

5. Hoznek A, Menard Y, Salomon L, Abbou CC: Update on laparoscopic and robotic radical prostatectomy. Curr Opin Urol. 2005; 15: 173-80.

6. Schuessler WW, Kavoussi LR, Clayman RV, Vancaille T: Laparoscopic radical prostatectomy: initial case report. J Urol. 1992: 147: 246A, Abstract no. 130.

7. Rassweiler J, Hruza M, Teber D, Su LM: Laparoscopic and robotic assisted radical prostatectomy--critical analysis of the results. Eur Urol. 2006; 49: 612-24.

8. Bollens R, Vanden Bossche M, Roumeguere T, Damoun A, Ekane S, Hoffmann P, et al.: Extraperitoneal laparoscopic radical prostatectomy. Results after 50 cases. Eur Urol. 2001; 40: 65-9.

9. Rassweiler J, Sentker L, Seemann O, Hatzinger M, Stock C, Frede T: Heilbronn laparoscopic radical prostatectomy. Technique and results after 100 cases. Eur Urol. 2001; 40: 54-64.

10. Türk I, Deger S, Winkelmann B, Schönberger B, Loening SA: Laparoscopic radical prostatectomy. Technical aspects and experience with 125 cases. Eur Urol. 2001; 40: 46-52; discussion 53.

11. De La Rosette JJ, Abbou CC, Rassweiler J, Laguna MP, Schulman CC: Laparoscopic radical prostatectomy: a European virus with global potentials. Arch Esp Urol. 2002; 55: 603-9.

12. Gill IS, Zippe CD: Laparoscopic radical prostatectomy: technique. Urol Clin North Am. 2001; 28: 423-36.

13. Vögeli TA, Burchardt M, Fornara P, Rassweiler J, Sulser T; Laparoscopic Working Group of the German Urological Association: Current laparoscopic practice patterns in urology: results of a survey among urologists in Germany and Switzerland. Eur Urol. 2002; 42: 441-6.

14. Protzel C, Pechoel M, Richter M, Zimmermann U, Klebingat K: Radikale Prostatektomie und pelvine Lymphadenektomie - aktuelle Therapiestrategien in Deutschland - Ergebnisse einer deutschlandweiten Umfrage. Urologe A. 2004; 43: S59, Abstract P klin 6.5 .

15. Rassweiler J, Stolzenburg J, Sulser T, Deger S, Zumbé J, Hofmockel G, et al.: Laparoscopic radical prostatectomy--the experience of the German Laparoscopic Working Group. Eur Urol. 2006; 49: 113-9.
16. Schulser T, Guillonneau B, Vallancien G, Gaston R, Piechaud T, Turk I: Complications and initial experience with 1228 laparoscopic radical prostatectomies at 6 European centers. J Urol 2001; 165(Suppl): 150, Abstract no. 615.

17. Erdogru T, Teber D, Frede T, Marrero R, Hammady A, Rassweiler J: The effect of previous transperitoneal laparoscopic inguinal herniorrhaphy on transperitoneal laparoscopic radical prostatectomy. J Urol. 2005; 173: 769-72.

18. Bhayani SB, Pavlovich CP, Strup SE, Dahl DM, Landman J, Fabrizio MD, et al.: Laparoscopic radical prostatectomy: a multi-institutional study of conversion to open surgery. Urology. 2004; 63: 99-102.

19. Artibani W, Grosso G, Novara G, Pecoraro G, Sidoti O, Sarti A, et al.: Is laparoscopic radical prostatectomy better than traditional retropubic radical prostatectomy? An analysis of peri-operative morbidity in two contemporary series in Italy. Eur Urol. 2003; 44: 4016.

20. Rassweiler J, Seemann O, Schulze M, Teber D, Hatzinger M, Frede T: Laparoscopic versus open radical prostatectomy: a comparative study at a single institution. J Urol. 2003; 169: 1689-93.

21. Bhayani SB, Pavlovich CP, Hsu TS, Sullivan W, Su LM: Prospective comparison of short-term convalescence: laparoscopic radical prostatectomy versus open radical retropubic prostatectomy. Urology. 2003; 61: 612-6.

22. Roumeguere T, Bollens R, Vanden Bossche M, Rochet D, Bialek D, Hoffman P, et al.: Radical prostatectomy: a prospective comparison of oncological and functional results between open and laparoscopic approaches. World J Urol. 2003; 20: 360-6.

23. Fornara P, Zacharias M: Minimal invasiveness of laparoscopic radical prostatectomy: reality or dream? Aktuelle Urol. 2004; 35: 395-405.

24. Brown JA, Garlitz C, Gomella LG, McGinnis DE, Diamond SM, Strup SE: Perioperative morbidity of laparoscopic radical prostatectomy compared with open radical retropubic prostatectomy. Urol Oncol. 2004; 22: 102-6.

25. Keller H, Janetschek G, Abukora F, Leeb K, Schmeller $\mathrm{N}$ : Technique of radical prostatectomy - a head to head comparison of retropubic, perineal and laparoscopic access - data on perioperative morbidity. Eur Urol Suppl. 2005; 4: 247, Abstract no. 980.

26. Keller H, Schmeller N, Janetschek G: Urinary continence after retropubic, perineal, and laparoscopic radical prostatectomy: prospective comparfative study. Eur Urol Suppl. 2005; 4: 103, Abstract no. 403. 
27. Guillonneau B, Rozet F, Cathelineau X, Lay F, Barret E, Doublet JD, et al.: Perioperative complications of laparoscopic radical prostatectomy: the Montsouris 3-year experience. J Urol. 2002; 167: 51-6.

28. Gonzalgo ML, Pavlovich CP, Trock BJ, Link RE, Sullivan W, Su LM: Classification and trends of perioperative morbidities following laparoscopic radical prostatectomy. J Urol. 2005; 174: 135-9; discussion 139.

29. Hoznek A, Salomon L, Olsson LE, Antiphon P, Saint F, Cicco A, et al.: Laparoscopic radical prostatectomy. The Créteil experience. Eur Urol. 2001; 40: 38-45.

30. Rassweiler J, Sentker L, Seemann O, Hatzinger M, Rumpelt HJ: Laparoscopic radical prostatectomy with the Heilbronn technique: an analysis of the first 180 cases. J Urol. 2001; 166: 2101-8.

31. Eden CG, Cahill D, Vass JA, Adams TH, Dauleh MI: Laparoscopic radical prostatectomy: the initial UK series. BJU Int. 2002; 90: 876-82.

32. Lein M, Stibane I, Mansour R, Hege C, Roigas J, Wille A, et al.: Complications, urinary continence, and oncologic outcome of 1000 laparoscopic transperitoneal radical prostatectomies-experience at the Charité Hospital Berlin, Campus Mitte. Eur Urol. 2006; 50: 1278-82; discussion 1283-4.

33. Agnelli G, Bolis G, Capussotti L, Scarpa RM, Tonelli F, Bonizzoni E, et al.: A clinical outcome-based prospective study on venous thromboembolism after cancer surgery: the @RISTOS project. Ann Surg. 2006; 243: 89-95.

34. Secin FP, Jiborn T, Bjartell AS, Fournier G, Salomon L, Abbou CC, et al.: Multi-institutional study of symptomatic deep venous thrombosis and pulmonary embolism in prostate cancer patients undergoing laparoscopic or robot-assisted laparoscopic radical prostatectomy. Eur Urol. 2008; 53: 134-45.

35. Ruiz L, Salomon L, Hoznek A, Vordos D, Yiou R, de la Taille A, et al.: Comparison of early oncologic results of laparoscopic radical prostatectomy by extraperitoneal versus transperitoneal approach. Eur Urol. 2004; 46: 50-4; discussion 54-6.

36. Erdogru T, Teber D, Frede T, Marrero R, Hammady A, Seemann O, et al.: Comparison of transperitoneal and extraperitoneal laparoscopic radical prostatectomy using match-pair analysis. Eur Urol. 2004; 46: 312-9; discussion 320.

37. Guillonneau B, el-Fettouh H, Baumert H, Cathelineau X, Doublet JD, Fromont G, et al.: Laparoscopic radical prostatectomy: oncological evaluation after 1,000 cases a Montsouris Institute. J Urol. 2003; 169: 12616.
38. Stolzenburg JU, Do M, Rabenalt R, Pfeiffer H, Horn L, Truss MC, et al.: Endoscopic extraperitoneal radical prostatectomy: initial experience after 70 procedures. J Urol. 2003; 169: 2066-71.

39. Cicco A, Salomon L, Hoznek H, Alame W, Saint F, Bralet MP, et al.: Carcinological risks and retroperitoneal laparoscopy. Eur Urol. 2000; 38: 606-12.

40. Wieder JA, Soloway MS: Incidence, etiology, location, prevention and treatment of positive surgical margins after radical prostatectomy for prostate cancer. J Urol. 1998; 160: 299-315.

41. Katz R, Salomon L, Hoznek A, de la Taille A, Antiphon P, Abbou CC: Positive surgical margins in laparoscopic radical prostatectomy: the impact of apical dissection, bladder neck remodeling and nerve preservation. $\mathrm{J}$ Urol. 2003; 169: 2049-52.

42. Salomon L, Sèbe P, De La Taille A, Vordos D, Hoznek A, Yiou R, et al.: Open versus laparoscopic radical prostatectomy: Part II. BJU Int. 2004; 94: 244-50.

43. Hull GW, Rabbani F, Abbas F, Wheeler TM, Kattan MW, Scardino PT: Cancer control with radical prostatectomy alone in 1,000 consecutive patients. J Urol. 2002; 167: 528-34.

44. Rassweiler J, Schulze M, Teber D, Marrero R, Seemann O, Rumpelt J, et al.: Laparoscopic radical prostatectomy with the Heilbronn technique: oncological results in the first 500 patients. J Urol. 2005; 173: 761-4.

45. Stolzenburg JU, Rabenalt R, DO M, Ho K, Dorschner W, Waldkirch E, et al.: Endoscopic extraperitoneal radical prostatectomy: oncological and functional results after 700 procedures. J Urol. 2005; 174: 1271-5; discussion 1275.

46. Touijer K, Kuroiwa K, Vickers A, Reuter VE, Hricak $\mathrm{H}$, Scardino PT, et al.: Impact of a multidisciplinary continuous quality improvement program on the positive surgical margin rate after laparoscopic radical prostatectomy. Eur Urol. 2006; 49: 853-8.

47. Pavlovich CP, Trock BJ, Sulman A, Wagner AA, Mettee LZ, Su LM: 3-year actuarial biochemical recurrence-free survival following laparoscopic radical prostatectomy: experience from a tertiary referral center in the United States. J Urol. 2008; 179: 917-21; discussion 921-2.

48. Anastasiadis AG, Salomon L, Katz R, Hoznek A, Chopin D, Abbou CC: Radical retropubic versus laparoscopic prostatectomy: a prospective comparison of functional outcome. Urology. 2003; 62: 292-7.

49. Guillonneau B, Cathelineau X, Doublet JD, Baumert $\mathrm{H}$, Vallancien G: Laparoscopic radical prostatectomy: assessment after 550 procedures. Crit Rev Oncol Hematol. 2002; 43: 123-33. 
50. Rassweiler J, Seemann O, Hatzinger M, Schulze M, Frede T: Technical evolution of laparoscopic radical prostatectomy after 450 cases. J Endourol. 2003; 17: 143-54.

51. Galli S, Simonato A, Bozzola A, Gregori A, Lissiani A, Scaburri A, et al.: Oncologic outcome and continence recovery after laparoscopic radical prostatectomy: 3 years' follow-up in a "second generation center". Eur Urol. 2006; 49: 859-65.

52. Rocco F, Carmignani L, Acquati P, Gadda F, Dell'Orto P, Rocco B, et al.: Early continence recovery after open radical prostatectomy with restoration of the posterior aspect of the rhabdosphincter. Eur Urol. 2007; 52: 37683.

53. Nguyen MM, Kamoi K, Stein RJ, Aron M, Hafron JM, Turna B, et al.: Early continence outcomes of posterior musculofascial plate reconstruction during robotic and laparoscopic prostatectomy. BJU Int. 2008; 101: 11359.

54. Curto F, Benijts J, Pansadoro A, Barmoshe S, Hoepffner JL, Mugnier C, et al.: Nerve sparing laparoscopic radical prostatectomy: our technique. Eur Urol. 2006; 49: 344-52.

55. Ong AM, Su LM, Varkarakis I, Inagaki T, Link RE, Bhayani SB, et al.: Nerve sparing radical prostatec- tomy: effects of hemostatic energy sources on the recovery of cavernous nerve function in a canine model. J Urol. 2004; 172: 1318-22.

56. Mulhall JP, Secin FP, Guillonneau B: Artery sparing radical prostatectomy--myth or reality? J Urol. 2008; 179: 827-31.

57. Fabrizio MD, Tuerk I, Schellhammer PF: Laparoscopic radical prostatectomy: decreasing the learning curve using a mentor initiated approach. J Urol. 2003; 169: 2063-5.

58. Colegrove PM, Winfield HN, Donovan JF Jr, See WA: Laparoscopic practice patterns among North American urologists 5 years after formal training. J Urol. 1999; 161: 881-6.

59. Skrekas T, Mochtar CA, Lagerveld BW, de Reijke TM, van Velthoven RF, Peltier A, et al.: Mentor-initiated approach in laparoscopic radical prostatectomy. J Endourol. 2006; 20: 831-5.

60. Stolzenburg JU, Rabenalt R, Do M, Horn LC, Liatsikos EN: Modular training for residents with no prior experience with open pelvic surgery in endoscopic extraperitoneal radical prostatectomy. Eur Urol. 2006; 49: 491-8; discussion 499-500.

61. Anderson JK, Murdock A, Cadeddu JA, Lotan Y: Cost comparison of laparoscopic versus radical retropubic prostatectomy. Urology. 2005; 66: 557-60.

Accepted after revision: December 18, 2008

\section{Correspondence address:}

Dr. Pierluigi Bove

University of Rome Tor Vergata

Viale Oxford 81

Rome, 00133, Italy

Fax: + 3906 2090-2975

E-mail: tasospao2003@yahoo.com

\section{EDITORIAL COMMENT}

The authors performed a good review of one of the popular techniques in urology. They summarize main aspects of the historical evolution, complications, functional and oncological results, learning curve and cost. The historical aspects are very well presented. The authors did a very good review of the continence and potency aspects in the laparoscopic prostatectomy. Several groups, especially in the USA, discharge the patients from the hospital the next day after the retropubic operation (1), which is comparable 
to laparoscopic prostatectomy. Lower blood loss and lower blood rate transfusion is the main advantage of the technique and is the only proven improvement. It is important to remember a great demand for a modular training program with a clinical proven usefulness for Urology fellows (2).

\section{REFERENCES}

1. Soloway MS: Frozen sections for positive margins? Eur Urol. 2006; 49: 950-1.

\section{EDITORIAL COMMENT}

In an era when fewer open and pure laparoscopic radical prostatectomies (LRP) are being performed in the United States, it is important to recall the gold standard in prostate surgery and also the original minimally invasive approach. The authors provide a comprehensive review of the current literature regarding LRP. The authors fairly report on a large number of LRP series reviewing intra-operative and peri-operative outcomes, oncologic data, continence and potency outcomes. The review outlines comparisons of LRP to open RRP either head to head or as compared to historical controls and the authors conclude, rightly so, apparent equivalence in intermediate outcomes with LRP groups reporting decreased blood loss, transfusion rate and shorter hospital stay. However, other important outcomes such as margins, continence and potency measures are not as convincingly equivalent for LRP and really remain in question.

The authors articulate that 50 cases are needed to plateau on the learning curve of LRP. In fact, we believe the protracted learning curve and technical difficulty of LRP is vastly understated. In fact, the majority of US references in this article come from institutions that no longer perform LRP. Truth be told, the largest single institutional radical prostatectomy series are now being reported with use of the daVinci surgical robot and outcomes as compared to open and as compared to LRP are similar if not superior in some variables (1-4). While the experienced surgeon
2. Stolzenburg JU, Rabenalt R, Do M, Horn LC, Liatsikos EN: Modular training for residents with no prior experience with open pelvic surgery in endoscopic extraperitoneal radical prostatectomy. Eur Urol. 2006; 49: 491-8; discussion 459-500.

\author{
Dr. Jens-Uwe Stolzenburg \\ Urologische Klinik und Poliklinik \\ Universitätsklinikum Leipzig AöR \\ Leipzig, Germany \\ E-mail:stolj@medizin.uni-leipzig.de
}

in laparoscopic prostatectomy may be capable of performing LRP, the wrist movements and three-dimensional vision that the robot provides certainly lends to a less physically challenging learning curve with equivalent surgical outcomes. A contemporary review of LRP should mention, as it did, the gold standard open RRP, but should also make at least reference to the latest innovation in minimally invasive prostatectomy, the daVinci robot assisted prostatectomy.

What is clearly illustrated in the present discussion is that excellent outcomes can be achieved with multiple surgical modalities. In the end, it is the surgeon's skill and not the tool used that makes the outcome. Regarding the surgical treatment for prostate cancer, there are many arrows in the quiver and it is up to the surgeon to choose what is appropriate for his/her patient.

\section{REFERENCES}

1. Wood DP, Schulte R, Dunn RL, Hollenbeck BK, Saur R, Wolf JS Jr, et al.: Short-term health outcome differences between robotic and conventional radical prostatectomy. Urology. 2007; 70: 945-9.

2. Smith JA Jr, Chan RC, Chang SS, Herrell SD, Clark PE, Baumgartner R, et al.: A comparison of the incidence and location of positive surgical margins in robotic assisted laparoscopic radical prostatectomy and open retropubic radical prostatectomy. J Urol. 2007; 178: 2385-9; discussion 2389-90. 
3. Badani KK, Kaul S, Menon M: Evolution of robotic radical prostatectomy: assessment after 2766 procedures. Cancer. 2007; 110: 1951-8.
4. Menon M, Shrivastava A, Kaul S, Badani KK, Fumo M, Bhandari M, et al.: Vattikuti Institute prostatectomy: contemporary technique and analysis of results. Eur Urol. 2007; 51: 648-57; discussion 657-8.

Dr. Joshua M Stern \& Dr. David I Lee Section of Robotic Urologic Surgery Penn Presbyterian Medical Center Philadelphia, Pennsylvania, USA E-mail:David.Lee@uphs.upenn.edu 